\title{
EFEITO DO CULTIVO DA SOJA NA DINÂMICA DA POPULAÇÃO BACTERIANA, EM SOLOS DE CERRADO1
}

\author{
JOÃO CARLOS PEREIRA ${ }^{2}$, MARIA CRISTINA PRATA NEVES ${ }^{3}$ e CARLOS ALBERTO TUÃO GAVA ${ }^{4}$
}

\begin{abstract}
RESUMO - Este trabalho teve por objetivo avaliar a influência do cultivo da soja sobre a dinâmica da população bacteriana, em dois solos de Cerrado do Estado de São Paulo, originalmente cobertos com Paspalum notatum (em Barretos) e Brachiaria decumbens (em São Carlos). Nesses solos, a densidade da população de bactérias em geral variou de $398,1 \times 10^{3}$ a $467,7 \times 10^{3}$ e de $123 \times 10^{3}$ a $218,8 \times 10^{3}$ ufc (unidades formadoras de colônias)/g de solo seco, respectivamente. O cultivo da soja, em ambos os solos, resultou em incrementos variados nos números de ufc/g de solo seco da população de bactérias em geral, das resistentes aos antibióticos estreptomicina e cloranfenicol, e de actinomicetos. A população de actinomicetos ocorreu no solo principalmente como esporos, e as variações das relações esporos/hifas entre os solos não-rizosférico e rizosférico não foram significativas. Os resultados evidenciam que o cultivo da soja influenciou de forma diferenciada a população desses solos.
\end{abstract}

Termos para indexação: Glycine max, densidade microbiana, actinomicetos, antibióticos, estreptomicina, cloranfenicol, microbiologia de solo.

\section{EFFECTS OF SOYBEAN CULTIVATION ON THE BACTERIAL POPULATION DYNAMICS IN CERRADO SOILS}

\begin{abstract}
The effect of soybean cultivation on the population dynamics of the bacterial community was evaluated in two "Cerrado" soils of São Paulo State, Brazil. The experimental areas, in the vicinities of the cities of São Carlos and Barretos, were previously cultivated, respectively, with Paspalum notatum and Brachiaria decumbens. The bacterial population densities in these soils varied from $398.1 \times 10^{3}$ to $467.7 \times 10^{3} \mathrm{cfu}$ (colony forming units) and from $123 \times 10^{3}$ to $218.8 \times 10^{3} \mathrm{cfu} / \mathrm{g}$ of dried soil, respectively, in São Carlos and Barretos soils. Soybean cultivation in both soils resulted in increments in the total bacterial population density, in the actinomycetes population, and in the bacterial population resistant to the antibiotics streptomycin and chloramphenicol. Actinomycetes were present in these soils mainly as spores. Soybean cultivation did not alter the actinomycetes spores/hyphae ratio when comparing rhizospheric and non-rhizospheric soils. The results show that soybean cultivation affected the bacterial population of these soils.

Index terms: Glycine max, microbial densities, actinomycetes, antibiotics, streptomycin, chloramphenicol, soil microbiology.
\end{abstract}

\footnotetext{
${ }^{1}$ Aceito para publicação em 23 de junho de 1999.

${ }^{2}$ Eng Agrôn., Ph.D., Embrapa-Centro Nacional de Pesquisa de Agrobiologia (CNPAB), Estrada Rio-São Paulo, km 47, Caixa Postal 74505, CEP 23851-970 Seropédica, RJ. E-mail: jpereira@cnpab.embrapa.br

${ }^{3}$ Bióloga, Ph.D., Embrapa-CNPAB. E-mail: mcpneves@cnpab.embrapa.br

${ }^{4}$ Eng. Agrôn., Mestrando em Ciência do Solo, Universidade Federal Rural do Rio de Janeiro, Estrada Rio-São Paulo, Km 47, CEP 23851-970 Seropédica, RJ
}

\section{INTRODUÇÃO}

A região do Cerrado apresenta características adequadas para a atividade agrícola, onde, pelo menos, 112 milhões de hectares de terras apresentam potencial para o cultivo agrícola (Peres et al., 1992).

As práticas agrícolas alteram as características físicas, químicas e biológicas determinantes das condições do solo, influenciando as diversas populações na comunidade microbiana. Essas modificações refletem-se na composição, atividade e biomassa da 
comunidade microbiana, uma vez que a permanência de uma população no ecossistema fica condicionada à sua habilidade de adaptação e de resposta a essas mudanças ambientais (Kirchner et al., 1993; Pereira et al., 1996).

As modificações no equilíbrio estabelecido entre as populações microbianas ocorrem principalmente em decorrência de alterações do $\mathrm{pH}$, da umidade, da aeração, da temperatura e da disponibilidade de nutrientes orgânicos e inorgânicos, pelo efeito isolado ou do somatório de dois ou mais fatores (Madsen, 1995).

As pesquisas direcionadas para esse tipo de informação são relativamente intensas em solos das regiões temperadas, mas incipientes nas regiões subtropicais e tropicais. Assim, as avaliações qualitativas e quantitativas das populações na comunidade microbiana nos solos são relevantes, tanto na caracterização das relações entre os diferentes grupos e espécies de microrganismos como na identificação de fatores ambientais que exercem influência no equilíbrio microbiológico dos solos.

O conhecimento dos efeitos dos cultivos agrícolas na dinâmica das populações na comunidade bacteriana nos solos é importante, por causa das transformações que esses microrganismos promovem, influenciando a qualidade dos produtos e a produtividade agrícola.

A densidade da população de microrganismos específicos pode ser estimada por meio de atributos que os microrganismos apresentam, e que possibilitam a sua diferenciação dos demais (Falcon et al.,1995; Pereira et al., 1996, 1999). A resistência intrínseca a antibióticos tem sido utilizada como técnica viável na caracterização da população bacteriana em determinados ecossistemas (Lovato et al., 1991; Pereira et al., 1991). Na comunidade de actinomicetos, as unidades formadoras de colônias das populações originárias de hifas e esporos podem ser usadas como parâmetros específicos em estudos ecológicos desses microrganismos nos solos (Herron \& Wellington, 1990; Pereira, 1995).

Esta pesquisa teve como objetivo avaliar o efeito do cultivo da soja na dinâmica da população bacteriana em solos de Cerrado, com vistas a futuras manipulações qualitativas e quantitativas da comunidade microbiana nos solos.

\section{MATERIAL E MÉTODOS}

Os experimentos foram conduzidos em solos de Cerrado (Latossolo Vermelho-Escuro) das regiões paulistas de Barretos (Fazenda Canaã) e de São Carlos (Fazenda Santa Fé). Foram utilizados os seguintes tratamentos: solos não cultivados, cobertos com Paspalum notatum (Barretos) e com Brachiaria decumbens (São Carlos); solos cultivados que foram convencionalmente preparados e corrigidos com aplicação de calcário dolomítico (1,6 t/ha), de superfosfato simples $\left(80 \mathrm{~kg} /\right.$ ha de $\left.\mathrm{P}_{2} \mathrm{O}_{5}\right)$ e de cloreto de potássio $\left(60 \mathrm{~kg} /\right.$ ha de $\left.\mathrm{K}_{2} \mathrm{O}\right)$, para o cultivo da soja $($ Glycine $\max (\mathrm{L}$.) Merrill) (Tabela 1). Na cultivar Doko foram inoculados $200 \mathrm{~g}$ de inoculante em turfa, contendo a mistura das estirpes $\mathrm{Br} 33$ (CB 1809) de Bradyrhizobium elkanii e $\mathrm{Br} 40$ (SEMIA 566) de Bradyrhizobium japonicum $/ 50$ kg de sementes. A semeadura foi feita em linhas com densidade de 30 sementes por metro e com espaçamento de $0,5 \mathrm{~m}$ entre linhas. Essas áreas foram dispostas em faixas e formadas por parcelas de $3 \mathrm{~m} \times 5 \mathrm{~m}$. O delineamento experimental utilizado foi o de blocos ao acaso, com quatro repetições.

As amostras de solo foram compostas por 20 subamostras, sendo transportadas em caixas de isopor em condições ambientais (Pereira et al.,1996), para avaliações nos laboratórios da Embrapa-Centro Nacional de Pesquisa de Agrobiologia. O solo homogeneizado de cada amostra composta também foi utilizado para determinação do teor de umidade, através de secagem em estufa a $105^{\circ} \mathrm{C}$, até peso constante. Outra fração foi destinada para avaliações químicas, seguindo-se os métodos descritos por Barreto et al. (1979)

As influências do cultivo da soja na comunidade bacteriana dos solos foram avaliadas aos 30,90 e 180 dias após a fertilização do solo. A densidade da população das bactérias em geral e das bactérias com resistência natural aos antibióticos foi avaliada por meio de diluições seriadas em placas de Petri contendo meio de cultura descrito por Thornton (1922) e suas populações estimadas em unidades formadoras de colônias (ufc)/g de solo seco. A população resistente aos antibióticos foi contabilizada em meio contendo $20 \mu \mathrm{g}$ e $40 \mu \mathrm{g}$ de estreptomicina ou de cloranfenicol $/ \mathrm{mL}$. Os antibióticos foram esterilizados por filtragem através de membrana de nitrato celulose com poros de $0,45 \mu \mathrm{m}$ de diâmetro e adicionados ao meio com temperatura em torno de $45^{\circ} \mathrm{C}$.

A população de actinomicetos foi contabilizada em meio de cultura descrito por Waksman (1961). Os actinomicetos foram diferenciados morfologicamente, considerando que as colônias desses microrganismos geralmente se apresentam como opacas e coriáceas, com penetração das hifas no substrato (Gottlieb, 1973; Miyadoh, 1997; Vobis,1997; 
Pereira et al., 1999). Nos meios de cultura, antes da esterilização, foi adicionado actidione (cycloheximide) suficiente para se obter a concentração final de $300 \mu \mathrm{g} / \mathrm{mL}$ (Panthier et al., 1979). Como parâmetro, utilizaram-se os números de unidades formadoras de colônias (ufc)/g de solo seco.

A dinâmica da população de actinomicetos oriunda de esporos e de hifas dos solos cultivados ou não da região de São Carlos foi avaliada aos 60,90, 120, 150 e 180 dias após a fertilização do solo. A metodologia utilizada foi a da resina de troca iônica descrita por Herron \& Wellington (1990). Para essas avaliações, as amostras contendo $10 \mathrm{~g}$ de solo foram transportadas e armazenadas em recipientes contendo $10 \mathrm{~mL}$ de uma solução esterilizada de glicerol a $10 \% \mathrm{v} / \mathrm{v}$ (Wellington \& Williams, 1978). A contagem da ufc da população de actinomicetos em solo rizosférico foi feita considerando-se o solo aderido às raízes e não liberado delas por uma leve agitação manual (Papavizas \& Lewis, 1983; Drozdowicz, 1991).

\section{RESULTADOS E DISCUSSÃO}

\section{Solo de Barretos}

O solo não cultivado com soja (com Paspalum notatum) apresentou densidade média da população de bactérias em geral, variando de $398,1 \times 10^{3}$ a $467,7 \times 10^{3} \mathrm{ufc} / \mathrm{g}$ de solo seco aos 90 e 30 dias após a fertilização do solo, respectivamente (Tabela 2). A densidade média da população bacteriana com resistência natural aos antibióticos estreptomicina e cloranfenicol nessa região foi menor. A densidade da população com resistência natural à estreptomicina variou entre $0,2 \times 10^{3} \mathrm{ufc} / \mathrm{g}$ de solo seco aos 180 dias, na concentração de $40 \mu \mathrm{g} / \mathrm{mL}$, e 117,5 x $10^{3}$ aos 30 dias, na concentração de $20 \mu \mathrm{g} / \mathrm{mL}$, enquanto a densidade da população resistente ao cloranfenicol oscilou entre $0,01 \times 10^{3}$ e $107,0 \times 10^{3} \mathrm{ufc} / \mathrm{g}$ de solo seco, aos 90 e 180 dias na concentração de $40 \mu \mathrm{g} / \mathrm{mL}$, e aos 30 dias na concentração de $20 \mu \mathrm{g} / \mathrm{mL}$, respectivamente. Densidades similares têm sido encontradas por outros autores em solos de Cerrado (Baldani et al., 1982; Pereira et al., 1996).

A densidade da população bacteriana resistente a $20 \mu \mathrm{ge} 40 \mu \mathrm{g}$ de estreptomicina e de cloranfenicol $/ \mathrm{mL}$ diminuiu durante o período de condução do experimento; esse decréscimo foi significativo 90 dias após a fertilização do solo. Tem-se observado que o nível de resistência aos antibióticos apresentados pelas células bacterianas pode estar associado às concentrações de antibióticos presentes nos solos (Baldani et al., 1982). Desta forma, tais resultados sugerem que aos 90 e 180 dias, a atividade dos antibióticos presentes no solo foram menores do que na avaliação inicial.

TABELA 1. Caracterização química dos solos de Cerrado das regiões paulistas de Barretos com Paspalum notatum e de São Carlos com Brachiaria decumbens e com cultivo de soja, aos 30, 90 e 180 dias após a fertilização.

\begin{tabular}{|c|c|c|c|c|c|c|c|c|}
\hline Solo & $\begin{array}{l}\text { Dias após } \\
\text { a fertilização } \\
\text { do solo }\end{array}$ & $\begin{array}{c}\mathrm{pH} \text { em } \mathrm{H}_{2} \mathrm{O} \\
(1: 2,5)\end{array}$ & $\begin{array}{r}\mathrm{Al} \\
----(\mathrm{m}\end{array}$ & $\begin{array}{r}\mathrm{Ca}+\mathrm{Mg} \\
\left.\mathrm{l}_{\mathrm{c}} / \mathrm{dm}^{3}\right)----\end{array}$ & $\begin{array}{c}\mathrm{P} \\
----\end{array}$ & $\begin{array}{c}\mathrm{K} \\
\text { 3) } \\
------\end{array}$ & $\mathrm{N}$ & $\mathrm{C}$ \\
\hline & & \multicolumn{7}{|c|}{ Barretos } \\
\hline \multirow[t]{3}{*}{ Com Paspalum notatum } & 30 & 5,4 & 2 & 25 & 5,1 & 89 & 0,80 & 10,4 \\
\hline & 90 & 5,7 & 0 & 36 & 8,5 & 82 & 1,00 & 9,3 \\
\hline & 180 & 5,8 & 0 & 43 & 13,0 & 96 & 1,10 & 13,0 \\
\hline \multirow[t]{3}{*}{ Cultivado com soja } & 30 & 5,9 & 1 & 32 & 4,2 & 91 & 0,90 & 10,0 \\
\hline & 90 & 5,8 & 0 & 39 & 6,8 & 133 & 0,90 & 9,5 \\
\hline & 180 & 5,6 & 0 & 41 & 4,6 & 142 & 1,00 & 12,5 \\
\hline \multicolumn{9}{|c|}{ São Carlos } \\
\hline \multirow[t]{3}{*}{ Com Brachiaria decumbens } & 30 & 4,6 & 7 & 12 & 14,0 & 15 & 0,55 & 7,2 \\
\hline & 90 & 4,7 & 6 & 13 & 12,9 & 14 & 0,59 & 6,4 \\
\hline & 180 & 4,9 & 5 & 17 & 9,8 & 24 & 0,53 & 7,7 \\
\hline \multirow[t]{3}{*}{ Cultivado com soja } & 30 & 6,7 & 0 & 38 & 60,7 & 15 & 0,60 & 7,4 \\
\hline & 90 & 6,7 & 0 & 48 & 66,7 & 19 & 0,61 & 6,5 \\
\hline & 180 & 6,3 & 0 & 43 & 89,4 & 16 & 0,61 & 8,0 \\
\hline
\end{tabular}


A densidade da população de actinomicetos variou de $234,4 \times 10^{3}$ a 724,4 × $10^{3} \mathrm{ufc} / \mathrm{g}$ de solo seco. Essas densidades são semelhantes às encontradas por outros autores em solos de Cerrado, em condições ambientais diversas (Coelho, 1976; Baldani et al., 1982; Raymundo Júnior, 1992; Pereira, 1995; Pereira et al., 1996; Raymundo Júnior \& Tauk-Tornisielo, 1997). Observa-se que aos 90 dias houve um aumento significativo da densidade da população desses microrganismos. Esse comportamento pode estar associado com o estresse provocado pela deficiência hídrica do solo, já que a umidade média das amostras do solo nesta coleta estava em torno de $6 \%$, resultante da ausência de chuvas na região nos 40 dias anteriores. Desta forma, a população de actinomicetos que apresentam como característica específica a sobrevivência em condições ambientais adversas, como períodos de seca dos solos (Nolan \& Cross, 1988; Miyadoh, 1997), foi beneficiada.

O cultivo da soja nesse solo resultou no desequilíbrio da comunidade bacteriana, aumentando os números médios de ufc/g de solo seco da população de bactérias em geral, das resistentes à estreptomicina e ao cloranfenicol e de actinomicetos (Tabela 3). Esses resultados não podem ser atribuídos ao efeito da calagem, já que esta alterou o $\mathrm{pH}$ do solo em apenas 0,5 unidades, aos 30 dias após a semeadura da soja, ao passo que aos 90 e 180 dias os pHs dos solos com Paspalum notatum e cultivado com soja foram semelhantes (Tabela 1).

Observa-se, também, que um decréscimo significativo da densidade da população de bactérias em

TABELA 2. Dinâmica da população bacteriana em solo de Cerrado com Paspalum notatum, da região de Barretos, $\mathbf{S P}^{1}$.

\begin{tabular}{|c|c|c|c|}
\hline \multirow[t]{2}{*}{ População bacteriana } & \multicolumn{3}{|c|}{ Dias após a fertilização do solo } \\
\hline & 30 & 90 & 180 \\
\hline & \multicolumn{3}{|c|}{ - $\left(\right.$ ufc x $10^{3} / \mathrm{g}$ solo seco) } \\
\hline Bactérias em geral & $467,7 \mathrm{aA}$ & $398,1 \mathrm{aA}$ & $407,4 \mathrm{aA}$ \\
\hline Resistente à estreptomicina $(20 \mu \mathrm{g} / \mathrm{mL})$ & $117,5 \mathrm{aAB}$ & $23,4 \mathrm{bB}$ & $1,6 \mathrm{bB}$ \\
\hline Resistente à estreptomicina ( $40 \mu \mathrm{g} / \mathrm{mL})$ & $72,4 \mathrm{aB}$ & $3,6 \mathrm{bC}$ & $0,2 \mathrm{cB}$ \\
\hline Bactérias em geral & $467,7 \mathrm{aA}$ & $398,1 \mathrm{aA}$ & $407,4 \mathrm{aA}$ \\
\hline Resistente ao cloranfenicol $(20 \mu \mathrm{g} / \mathrm{mL})$ & $107,0 \mathrm{aAB}$ & $5,2 \mathrm{bB}$ & $5,4 \mathrm{bB}$ \\
\hline Resistente ao cloranfenicol $(40 \mu \mathrm{g} / \mathrm{mL})$ & $38,9 \mathrm{aB}$ & $0,01 \mathrm{bC}$ & $0,01 \mathrm{bC}$ \\
\hline Actinomicetos & $275,4 b$ & 724,4 a & $234,4 \mathrm{c}$ \\
\hline
\end{tabular}

geral, aos 90 dias, pode estar associado com a deficiência hídrica do solo, potencializado pelos efeitos resultantes das mudanças na cobertura vegetal do solo (Drozdowicz, 1991; Madsen, 1995).

\section{Solo de São Carlos}

No solo não cultivado com soja (com Brachiaria decumbens), a densidade média da população de bactérias em geral variou de $117,5 \times 10^{3}$ a $218,8 \times 10^{3} \mathrm{ufc} / \mathrm{g}$ de solo seco (Tabela 4), ao passo que a densidade da população com resistência natural à estreptomicina foi menor, oscilando entre $0,2 \times 10^{3} \mathrm{ufc} / \mathrm{g}$ solo seco, aos 180 dias após a fertilização do solo, e $18,6 \times 10^{3} \mathrm{ufc} / \mathrm{g}$ de solo seco aos 30 dias, na concentração de $40 \mu \mathrm{g}$ deste antibiótico $/ \mathrm{mL}$. Em relação ao cloranfenicol, a menor densidade de $0,001 \times 10^{3} \mathrm{ufc} / \mathrm{g}$ de solo seco foi obtida na concentração de $40 \mu \mathrm{g} / \mathrm{mL}$ aos 180 dias, e a maior, de $45,7 \times 10^{3} \mathrm{ufc} / \mathrm{g}$ de solo seco na concentração de $20 \mu \mathrm{g} / \mathrm{mL}$, aos 30 dias

Aos 30 dias, as densidades das populações bacterianas com resistência natural a $20 \mu \mathrm{g}$ e $40 \mu \mathrm{g}$ de estreptomicina e de cloranfenicol $/ \mathrm{mL}$ foram semelhantes, o que evidencia um possível acúmulo desses antibióticos no solo, em níveis próximos à concentração de $40 \mu \mathrm{g} / \mathrm{mL}$. Por outro lado, nas avaliações subseqüentes, o mesmo efeito não é observado, visto que os números médios de ufc das bactérias com resistência natural a $20 \mu \mathrm{g}$ de estreptomicina e cloranfenicol $/ \mathrm{mL}$ foram significativamente superiores a $40 \mu \mathrm{g}$ desses antibióticos/mL.

TABELA 3. Dinâmica da população bacteriana em solo de Cerrado cultivado com soja, da região de Barretos, $\mathrm{SP}^{1}$.

\begin{tabular}{lrrc}
\hline População bacteriana & \multicolumn{3}{c}{ Dias após a fertilização do solo } \\
\cline { 2 - 4 } & \multicolumn{1}{c}{30} & \multicolumn{1}{c}{90} & 180 \\
\hline & $-----(u f c * *$ & $10^{3} / \mathrm{g}$ solo seco) ------ \\
Bactérias em geral & $1737,8 \mathrm{aA}$ & $269,1 \mathrm{bA}$ & $1122,0 \mathrm{abA}$ \\
Resistente à estreptomicina $(20 \mu \mathrm{g} / \mathrm{mL})$ & $407,4 \mathrm{aB}$ & $3,5 \mathrm{bC}$ & $16,6 \mathrm{bB}$ \\
Resistente à estreptomicina $(40 \mu \mathrm{g} / \mathrm{mL})$ & $309,0 \mathrm{aB}$ & $22,9 \mathrm{bB}$ & $11,5 \mathrm{bB}$ \\
\hline Bactérias em geral & $1737,8 \mathrm{aA}$ & $269,1 \mathrm{bA}$ & $1122,0 \mathrm{abA}$ \\
Resistente ao cloranfenicol $(20 \mu \mathrm{g} / \mathrm{mL})$ & $549,5 \mathrm{aB}$ & $12,6 \mathrm{bB}$ & $5,4 \mathrm{cB}$ \\
Resistente ao cloranfenicol $(40 \mu \mathrm{g} / \mathrm{mL})$ & $354,8 \mathrm{aC}$ & $3,7 \mathrm{bB}$ & $0,1 \mathrm{bC}$ \\
\hline Actinomicetos & $501,2 \mathrm{a}$ & $309,0 \mathrm{~b}$ & $281,8 \mathrm{~b}$ \\
\hline \multirow{2}{*}{ Médias seguidas de mesma letra, maiúsculas nas colunas e minúscula }
\end{tabular}

as linhas, não diferem significativamente $(\mathrm{P}>0,05)$ pelo teste de Tukey. 
Tem-se verificado que as atividades dos antibióticos nos solos podem estar relacionadas com fatores ambientais e com os minerais do solo (Claus \& Filip, 1990). Assim, esses resultados estariam associados com a intensidade de adsorção desses antibióticos pelas argilas do solo. Antibióticos básicos, como a estreptomicina, e neutro, como o cloranfenicol, são adsorvidos por argilas do tipo caulinita (Soulides, 1965), predominante nos solos de Cerrado (Rodrigues \& Klamt, 1978).

O cultivo da soja neste solo resultou no desequilíbrio das populações na comunidade bacteriana (Tabela 5). Em relação ao solo não cultivado, houve um aumento no número médio de ufc/g de solo seco, da população de bactérias em geral, das resistentes aos antibióticos, e de actinomicetos; esse efeito é observado até aos 180 dias após a fertilização do solo. O desequilíbrio na comunidade bacteriana pode estar associado com as variações no ambiente microbiano, em conseqüência, principalmente, das modificações da cobertura vegetal e do $\mathrm{pH}$ do solo (Tabela 1), cujos efeitos influenciam a composição qualitativa e quantitativa da comunidade microbiana (Sá et al., 1983; Cattelan \& Vidor, 1990; Pereira et al., 1996).

Deve-se considerar que o $\mathrm{pH}$, além de estar influenciando a estabilidade química dos antibióticos (Mahler \& Bezdicek, 1978), também tem influência direta na população de actinomicetos nos solos (Gray \& Williams, 1975), cuja densidade geralmente está relacionada inversamente com a concentração iônica do hidrogênio no solo (Crawford et al., 1993). A faixa

TABELA 4. Dinâmica da população bacteriana em solo de Cerrado com Brachiaria decumbens, da região de São Carlos, SP1 .

\begin{tabular}{|c|c|c|c|}
\hline \multirow[t]{2}{*}{ População bacteriana } & \multicolumn{3}{|c|}{ Dias após a fertilização do solo } \\
\hline & 30 & 90 & 180 \\
\hline & \multicolumn{3}{|c|}{---- $\left(\right.$ ufc* $^{*} \times 10^{3} / \mathrm{g}$ solo seco) --- } \\
\hline Bactérias em geral & $218,8 \mathrm{aA}$ & $123,0 \mathrm{bA}$ & $117,5 \mathrm{bA}$ \\
\hline Resistente à estreptomicina $(20 \mu \mathrm{g} / \mathrm{mL})$ & $13,5 \mathrm{aB}$ & $13,5 \mathrm{aB}$ & $5,4 \mathrm{aB}$ \\
\hline Resistente à estreptomicina $(40 \mu \mathrm{g} / \mathrm{mL})$ & $18,6 \mathrm{aB}$ & $3,2 \mathrm{aC}$ & $0,2 \mathrm{bC}$ \\
\hline Bactérias em geral & $218,8 \mathrm{aA}$ & $123,0 \mathrm{bA}$ & $117,5 \mathrm{bA}$ \\
\hline Resistente ao cloranfenicol $(20 \mu \mathrm{g} / \mathrm{mL})$ & $45,7 \mathrm{aB}$ & $1,4 \mathrm{bB}$ & $2,1 \mathrm{bB}$ \\
\hline Resistente ao cloranfenicol $(40 \mu \mathrm{g} / \mathrm{mL})$ & $22,4 \mathrm{aB}$ & $0,01 \mathrm{bC}$ & $0,001 \mathrm{bC}$ \\
\hline Actinomicetos & $123,0 \mathrm{~b}$ & $79,4 \mathrm{~b}$ & $489,8 \mathrm{a}$ \\
\hline
\end{tabular}

ótima de $\mathrm{pH}$ para o desenvolvimento desses microrganismos está entre 6,5 e 8,0, e o pH 5,0 é limitante para a maioria das espécies (Gray \& Williams, 1975).

Tem-se observado que no Cerrado, a freqüência da população de actinomicetos na comunidade microbiana pode variar de $75 \%$ a $94 \%$ (Coelho \& Drozdowicz, 1978), e que a densidade dessa população aumenta rapidamente após a calagem (Baldani et al., 1982), especialmente do gênero Streptomyces, que apresenta espécies conhecidas como produtoras de estreptomicina e de outros antibióticos (Wellington \& Toth, 1994; Arai, 1997; Kudo, 1997).

Dada a grande quantidade de amostras a serem analisadas, optou-se por avaliar a dinâmica das populações de actinomicetos oriundas de esporos e de hifas somente no solo da região de São Carlos. Desta forma, a densidade média obtida na fração esporos variou de $14,4 \times 10^{3}$ a $28,8 \times 10^{3}$ ufc/g de solo seco, e na fração hifas, de $9,8 \times 10^{3}$ e 20,4 × $10^{3} \mathrm{ufc} / \mathrm{g}$ de solo seco.

No solo não cultivado, as relações esporos/hifas variaram de 1,01 a 1,08, aos 90 e 150 dias após a semeadura da soja, respectivamente, no solo rizosférico (Fig. 1). Esses dados são semelhantes aos obtidos em solo de Cerrado submetido a manejos agrícolas distintos, onde foi observado que as relações esporos/hifas variaram de 0,4 a 2,6 (Pereira, 1995).

Observa-se que as variações das relações esporos/hifas entre os solos não-rizosférico e rizosférico não são significativas, exceto aos 150 dias, quando a relação esporos/hifas do solo rizosférico foi superior ao solo não-rizosférico, conseqüência

TABELA 5. Dinâmica da população bacteriana em solo de Cerrado cultivado com soja, da região de São Carlos, $\mathrm{SP}^{\mathbf{1}}$.

\begin{tabular}{|c|c|c|c|}
\hline \multirow[t]{2}{*}{ População bacteriana } & \multicolumn{3}{|c|}{ Dias após a fertilização do solo } \\
\hline & 30 & 90 & 180 \\
\hline & \multicolumn{3}{|c|}{ - $\left(\mathrm{ufc}^{*} \times 10^{3} / \mathrm{g}\right.$ solo seco) } \\
\hline Bactérias em geral & $1230,3 \mathrm{aA}$ & $467,7 \mathrm{bA}$ & $776,2 \mathrm{bA}$ \\
\hline Resistente à estreptomicina ( $20 \mu \mathrm{g} / \mathrm{mL})$ & $346,7 \mathrm{bB}$ & $41,7 \mathrm{bB}$ & $17,1 \mathrm{bB}$ \\
\hline Resistente à estreptomicina ( 40 g/mL) & $114,8 \mathrm{aC}$ & $40,7 \mathrm{abB}$ & $8,5 \mathrm{bC}$ \\
\hline Bactérias em geral & $1230,3 \mathrm{aA}$ & $467,7 \mathrm{bA}$ & $776,2 \mathrm{bA}$ \\
\hline Resistente ao cloranfenicol $(20 \mu \mathrm{g} / \mathrm{mL})$ & $158,5 \mathrm{aB}$ & $53,7 \mathrm{bB}$ & $11,2 \mathrm{bB}$ \\
\hline Resistente ao cloranfenicol $(40 \mu \mathrm{g} / \mathrm{mL})$ & $95,5 \mathrm{aC}$ & $0,4 \mathrm{bC}$ & $0,1 \mathrm{bC}$ \\
\hline Actinomicetos & $416,9 \mathrm{a}$ & $147,9 \mathrm{~b}$ & $501,2 \mathrm{a}$ \\
\hline
\end{tabular}

1 Médias seguidas de mesma letra, maiúscula nas colunas e minúscula nas linhas, não diferem significativamente $(\mathrm{P}>0,05)$ pelo teste de Tukey. 
simultânea do aumento do número de ufc provenientes da fração esporo e diminuição do número de ufc da fração hifa, ambas variações ocorridas no solo rizosférico. Isso evidencia que o solo rizosférico apresentou condições mais estressantes para o desenvolvimento das populações de actinomicetos. $\mathrm{O}$ aumento do número de ufc provenientes da fração esporos pode estar associado a essas condições, considerando-se que os esporos são estruturas de resistência que permitem a tais microrganismos sobreviverem em condições ambientais desfavoráveis (Mayfield et al., 1972; Miyadoh, 1997).

No solo cultivado com soja, as relações esporos/hifas do solo rizosférico e não-rizosférico foram maiores aos 120, 150 e 180 dias após a fertilização do solo, variando de 1 aos 90 dias a 1,07 aos 180 dias (Fig. 2). Observa-se, também, que as variações das relações esporos/hifas entre os solos nãorizosférico e rizosférico não são significativas. Tal comportamento é semelhante ao observado anteriormente, no solo não cultivado (coberto com Brachiaria decumbens), e confirma observações anteriores de que a população de actinomicetos ocorre nos solos, principalmente na forma de esporos (Mayfield et al., 1972; Pereira, 1995), sendo responsáveis pela maioria das unidades formadoras de colônias em meio de cultura (Pereira, 1995).

Na população de actinomicetos, as influências dos fatores ambientais resultam em modificações morfológicas das estruturas de esporos e hifas, pois fatores estressantes determinam mudanças nas características fisiológicas e morfogenéticas das colônias, como a produção de esporos (Kalakoutskii \& Pouzharitskaja, 1973; Vobis, 1997). Assim, a produção mais elevada de esporos pode estar relacionada com as condições necessárias para a sua germinação, que requer especificidade em relação ao $\mathrm{pH}$ do solo (Gray \& Williams, 1975), à disponibilidade de nutrientes no solo (Wellington et al., 1990) ou ao efeito rizosférico (Drozdowicz, 1991; Bolton Junior et al., 1993). Deve-se ainda destacar que o número de esporos produzidos também pode estar associado com a diversidade morfológica da população de actinomicetos presente no solo, pois o gênero, as famílias ou mesmo as estirpes podem apresentar esporulações individualizadas, em cadeias ou em esporângios (Vobis, 1997).

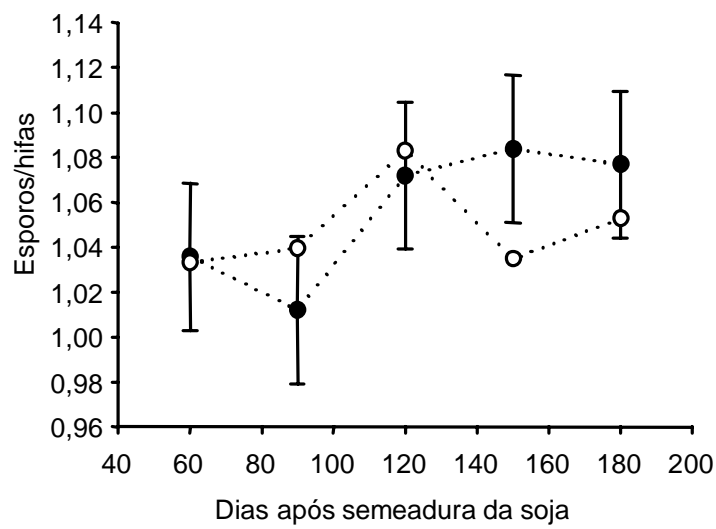

- Solo rizosférico

o ' Solo não-rizosférico

FIG. 1. Dinâmica das relações das populações de actinomicetos oriundas de esporos e hifas, em solo não cultivado, coberto com Brachiaria decumbens, na região de São Carlos, SP.

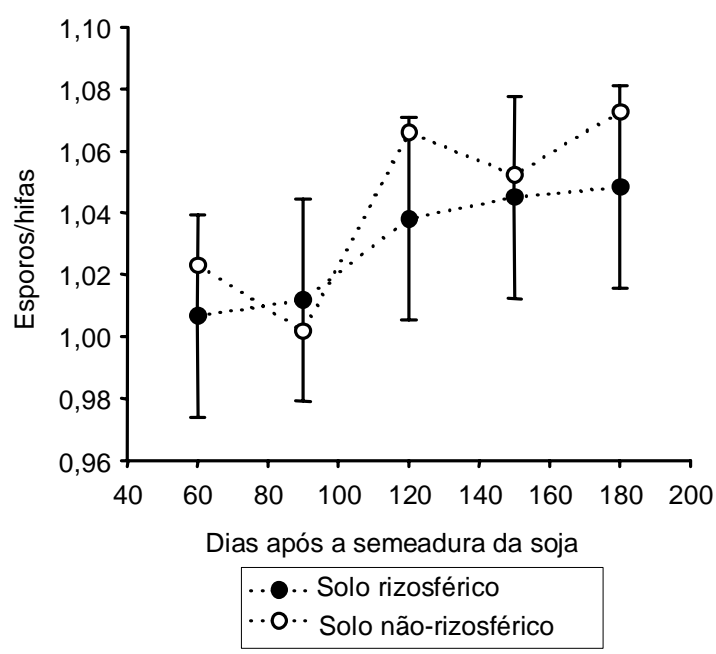

FIG. 2. Dinâmica das relações das populações de actinomicetos oriundas de esporos e hifas, em solo cultivado com soja, na região de São Carlos, SP.

\section{CONCLUSÃO}

O cultivo da soja em solos de Cerrado das regiões paulistas de Barretos e de São Carlos incrementa de maneira diferenciada a densidade da população de bactérias em geral, das resistentes a $20 \mu \mathrm{g}$ e $40 \mu \mathrm{g}$ de 
estreptomicina e cloranfenicol/mL, e da população de actinomicetos.

\section{REFERÊNCIAS}

ARAI, T. What are actinomycetes? In: MIYADOH, S (Ed.). Atlas of actinomycetes. Tokyo : Asakura, 1997. p.176-179.

BALDANI, J.I.; BALDANI, V.L.D.; XAVIER, D.F.; BODDEY, R.M.; DÖBEREINER, J. Efeito da calagem no número de actinomicetos e na porcentagem de bactérias resistentes à estreptomicina na rizosfera de milho, trigo e feijão. Revista de Microbiologia, São Paulo, v.13, n.3, p.250-263, 1982

BARRETO, W. de O.; DURIEZ, M.A. de M.; JOHAS, R.A.L. Análises químicas. In: EMBRAPA. Serviço Nacional de Levantamento e Conservação de Solos (Rio de Janeiro, RJ). Manual de métodos de análise do solo. Rio de Janeiro : Embrapa-SNLCS, 1979. parte 2

BOLTON JUNIOR, H.; FREDICKSON, J.K.; ELLIOTT, L.F. Microbial ecology of the rizosphere. In: METTING JUNIOR, F.B. (Ed.). Soil microbial ecology: applications in agricultural and environmental management. New York : M. Dekker, 1993. p.27-63. (Books in soils, plants, and the environmental).

CATTELAN, A.J.; VIDOR, C. Sistemas de culturas e a população microbiana do solo. Revista Brasileira de Ciência do Solo, Campinas, v.14, p.125-132, 1990 .

CLAUS, H.; FILIP, Z. Effects of clays and other solids on the activity of phenoloxidases produced by some fungi and actinomycetes. Soil Biology \& Biochemistry, Elmsford, v.22, n.4, p.483-488, 1990.

COELHO, R.R.R. Ocorrência de actinomicetos em solos de cerrado, capazes de utilizar compostos aromáticos. Rio de Janeiro : UFRJ, 1976. 111p. Dissertação de Mestrado.

COELHO, R.R.R.; DROZDOWICZ, A. The occurrence of actinomycetes in a Cerrado soil in Brazil. Révue d'Ecologie et de Biologie du Sol, Montrouge, v.15, n. 4, p.459-473, 1978.

CRAWFORD, D.I.; LYNCH, J.M.; WHIPPS, J.M.; OUSLEY, M.A. Isolation and characterization of actinomycete antagonists of a fungal root pathogen. Applied and Environmental Microbiology, Washington, v.59, p.3899-3905, 1993

DROZDOWICZ, A.G. Microbiologia ambiental. In: ROITMAN, I.; TRAVASSOS, I.R.; AZEVEDO, J.L.
(Ed.). Tratado de microbiologia. Rio de Janeiro Manole, 1991. v.2, p.1-102.

FALCON, M.A.; RODRIGUEZ, A.; CARNICERO, A.; REGALADO, V;; PERESTELO, F.; MILSTEIN, O; FUENTE, G. de la. Isolation of microorganisms with lignin transformation potential from soil of Tenerife Island. Soil Biology \& Biochemistry, Elmsford, v.27, p.121-126, 1995.

GOTTLIEB, D. General consideration and implications of the actinomycetales. In: SYKES, G.; SKINNER, F.A. (Ed.). Actinomycetales: characteristics and practical importance. London : Academic, 1973. p. $1-10$

GRAY, T.R.G.; WILLIAMS, S.T. Soil microorganisms 2.ed. London : Longman, 1975. 240p.

HERRON, P.R.; WELLINGTON, E.M.H. New method for extraction of streptomycete spores from soil and application to the study of lysogeny in sterile amended and nonsterile soil. Applied and Environmental Microbiology, Washington, v.56, n.5, p.1406-1412, 1990

KALAKOUTSKII, L.V.; POUZHARITSKAJA, L.M. The streptomyces spore: its distinct features and germinal behaviour. In: SYKES, G.; SKINNER, F.A (Ed.). Actinomycetales: characteristics and practical importance. London : Academic, 1973. p.155-178. (The Society for Applied Bacteriology Symposium Series, 2).

KIRCHNER, M.J.; WOLLUM, A.G.; KING, L.D. Soil microbial populations and activities in reduced chemical input agroecosystems. Soil Science Society of America. Journal, Madison, v.57, p.1289-1295, 1993

KUDO, T. Family Streptomycetaceae In: MIYADOH, S. (Ed.). Atlas of actinomycetes. Tokyo : Asakura, 1997. p.122-155.

LOVATO, P.E.; PEREIRA, J.C.; VIDOR, C. Sobrevivência de Rhizobium leguminosarum bv. phaseoli em solo e sua relação com a ocorrência em nódulos e fixação de nitrogênio em feijoeiro. Revista Brasileira de Ciência do Solo, Campinas, v.5, n.3, p.227282,1991

MADSEN, E.L. Impacts of agricultural practices on subsurface microbial ecology. Advances in Agronomy, San Diego, v.54, p.1-67, 1995.

MAHLER, R.L.; BEZDICEK, D.F. Diversity of Rhizobium leguminosarum in Palouse of Eastern Washington. Applied and Environmental Microbiology, Washington, v.36, p.780-782, 1978.

Pesq. agropec. bras., Brasília, v.35, n.6, p.1183-1190, jun. 2000 
MAYFIELD, C.I.; WILLIAMS, S.T.; RUDDICK, S.M.; HATFIELD, H.L. Studies on the ecology of actinomycetes in soil. IV. Observations on the form and growth of streptomycetes in soil. Soil Biology \& Biochemistry, Elmsford, v.4, p.79-91, 1972

MIYADOH, S. Morphology and phylogeny of actinomycetes. In: MIYADOH, S. (Ed.). Atlas of actinomycetes. Tokyo : Asakura, 1997. p.198-199.

NOLAN, R.D.; CROSS, T. Isolation and screening of actinomycetes. In: GOODFELLOW, M.; WILLIAMS, S.T.; MORDARSKI, M. (Ed.). Actinomycetes in biotechnology. London : Academic, 1988. p.1-32.

PANTHIER, J.J.; DIEM. H.G.; DOMMERGUES, Y. Rapid method to enumerate and isolate soil actinomycetes antagonistic towards rhizobia. Soil Biology \& Biochemistry, Elmsford, v.11, p.443445, 1979

PAPAVIZAS, G.C.; LEWIS, J.A. Physiological and biocontrol characteristics of stable mutants of Trichoderma viride resistents to $\mathrm{MBC}$ fungicides. Phytopathology, Saint Paul, v.73, p.407-411, 1983.

PEREIRA, J.C. Ecologia da comunidade bacteriana em solos de cerrados. Itaguaí : UFRRJ, 1995. 172p. Tese de Doutorado.

PEREIRA, J.C.; NEVES, M.C.P.; DROZDOWICZ, A Influência da antibiose exercida por actinomicetos às estirpes de Bradyrhizobium spp., na nodulação da soja. Pesquisa Agropecuária Brasileira, Brasília, v.34, n.1, p.99-108, jan. 1999.

PEREIRA, J.C.; NEVES, M.C.P.; DROZDOWICZ, A Quantificações das populações de bactérias em geral, de bactérias resistentes a antibióticos e de actinomicetos em solos. Seropédica : EmbrapaCNPAB, 1996. 20p. (Embrapa-CNPAB. Documentos, 26).

PEREIRA, J.C.; VIDOR, C.; LOVATO, P.E.; PENTEADO, A.F. Simbiose entre feijão e estirpes de Rhizobium leguminosarum bv. phaseoli, sensíveis e resistentes a antibióticos e fungicidas. Pesquisa Agropecuária Brasileira, Brasília, v.26, n.7, p.10971105, jul. 1991.

PERES, J.R.R.; SUHET, A.R.; VARGAS, M.A.T. Fixação do $\mathrm{N}_{2}$ em leguminosas cultivadas em solos de cerrados. In: CARDOSO, E.J.B.N.; TSAI, S.M.; NEVES, M.C.P. (Ed.). Microbiologia do solo. Campinas : Sociedade Brasileira de Ciência do Solo, 1992. p.213-218.

RAYMUNDO JÚNIOR, O.R. Fungos filamentosos, actinomicetos e ácidos húmicos, em diferentes profundidades de Latossolo Vermelho-Amarelo textura média em área de cerrado, no município de Corumbataí, SP. Rio Claro : UNESP, 1992. 149p. Dissertação de Mestrado.

RAYMUNDO JÚNIOR, O.R.; TAUK-TORNISIELO, S.M. Occurrence of hyphomycetes and actinomycetes in red-yellow latosol from a cerrado region in Brazil. Revista de Microbiologia, São Paulo, v.28, p.197-203, 1997

RODRIGUES, T.E.; KLAMT, E. Mineralogia e genese de uma seqüência de solos do Distrito Federal. Revista Brasileira de Ciência do Solo, Campinas, v.2, p.132-139, 1978.

SÁ, N.M.H.; SCOTTI, M.R.M.M.L.; VARGAS, M.A.T.; DÖBEREINER, J. Resistência natural à estreptomicina e eficiência de estirpes de Rhizobium nativas nos cerrados associadas a Stylosanthes. Pesquisa Agropecuária Brasileira, Brasília, v.18, n.3, p.213-218, mar. 1983

SOULIDES, D.A. Antibiotics in soils. VII. Production of streptomycin and tetracyclines in soil. Soil Science, Baltimore, v.100, p.200-206, 1965.

THORNTON, H.G. On the development of a standardized agar medium for counting soil bacteria with special regard to the repression of spreading colonies. Annals of Applied Biology, Cambridge, Grã-Bretanha, v.9, p.241-274, 1922.

VOBIS, G. Morphology of actinomycetes. In MIYADOH, S. (Ed.). Atlas of actinomycetes Tokyo : Asakura, 1997. p.180-191

WAKSMAN, S.A. The actinomycetes, classification, identification and descriptions of genera and species. Baltimore : The Williams \& Wilkins, 1961. $260 \mathrm{p}$.

WELLINGTON, E.M.H.; CRESSWELL, N.; SAUNDERS, V.A. Growth and survival of streptomycete inoculants and extent of plasmid transfer in sterile and non-sterile soil. Applied and Environmental Microbiology, Washington, v.56, n.5, p.1413-1419, 1990 .

WELLINGTON, E.M.H.; TOTH, I.K. Actinomycetes. In: WEAVER, R.W.; ANGLE, J.S.; BOTTOMLEY, P.S.; BEZDICEK, D.; SMITH, S.; TABATABAI, A.; WOLLUM, A. (Ed.). Methods of soil analysis. New York : Soil Science Society of America, 1994 p.269-290 (SSSA. Book Series, 5)

WELLINGTON, E.M.H.; WILLIAMS, S.T. Preservation of actinomycete inoculum in frozen glycerol. Microbios Letters, Cambridge, Grã-Bretanha, v.6, p.151-157, 1978. 